October 2002 • NREL/SR-560-32499

\title{
State Electricity Regulatory Policy and Distributed Resources: \\ Distributed Resource Distribution Credit Pilot Programs - Revealing the Value to Consumers and Vendors
}

D. Moskovitz, C. Harrington, W. Shirley,

R. Cowart, R. Sedano, and F. Weston

The Regulatory Assistance Project

Gardiner, Maine

Montpelier, Vermont

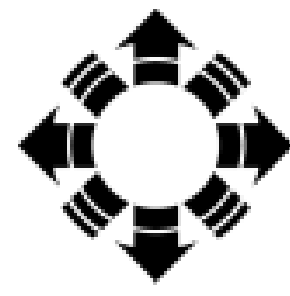

NREI

National Renewable Energy Laboratory

1617 Cole Boulevard

Golden, Colorado 80401-3393

NREL is a U.S. Department of Energy Laboratory

Operated by Midwest Research Institute $\bullet$ Battelle $\bullet$ Bechtel

Contract No. DE-AC36-99-G010337 


\section{State Electricity Regulatory Policy and Distributed Resources: \\ Distributed Resource \\ Distribution Credit Pilot Programs - Revealing the Value to Consumers and Vendors}

D. Moskovitz, C. Harrington, W. Shirley,

R. Cowart, R. Sedano, and F. Weston

The Regulatory Assistance Project

Gardiner, Maine

Montpelier, Vermont

NREL Technical Monitor: Thomas Basso

Prepared under Subcontract No. NAD-1-30605-03
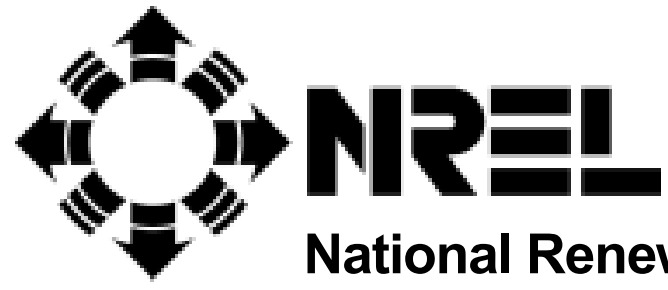

National Renewable Energy Laboratory

1617 Cole Boulevard

Golden, Colorado 80401-3393

NREL is a U.S. Department of Energy Laboratory

Operated by Midwest Research Institute $\bullet$ Battelle $\bullet$ Bechtel

Contract No. DE-AC36-99-G010337 


\section{NOTICE}

This report was prepared as an account of work sponsored by an agency of the United States government. Neither the United States government nor any agency thereof, nor any of their employees, makes any warranty, express or implied, or assumes any legal liability or responsibility for the accuracy, completeness, or usefulness of any information, apparatus, product, or process disclosed, or represents that its use would not infringe privately owned rights. Reference herein to any specific commercial product, process, or service by trade name, trademark, manufacturer, or otherwise does not necessarily constitute or imply its endorsement, recommendation, or favoring by the United States government or any agency thereof. The views and opinions of authors expressed herein do not necessarily state or reflect those of the United States government or any agency thereof.

Available electronically at http://www.osti.gov/bridge

Available for a processing fee to U.S. Department of Energy

and its contractors, in paper, from:

U.S. Department of Energy

Office of Scientific and Technical Information

P.O. Box 62

Oak Ridge, TN 37831-0062

phone: 865.576.8401

fax: 865.576.5728

email: reports@adonis.osti.gov

Available for sale to the public, in paper, from:

U.S. Department of Commerce

National Technical Information Service

5285 Port Royal Road

Springfield, VA 22161

phone: 800.553.6847

fax: 703.605.6900

email: orders@ntis.fedworld.gov

online ordering: http://www.ntis.gov/ordering.htm 


\section{Foreword}

This report is one in a series of four that discusses aspects of state regulatory policy and the potential development of cost-effective distributed resources. These reports were prepared by The Regulatory Assistance Project under contract to the National Renewable Energy Laboratory (see Annual Technical Status Report of the Regulatory Assistance Project: September 2000September 2001, NREL/SR-560-32733). The work is a part of a larger U.S. Department of Energy initiative designed to further the development and safe and reliable deployment of distributed resources within the nation's electricity system.

Distributed resources offer many economic and reliability benefits to customers, utilities, and society as a whole. But in some very important ways, our state regulatory practices inadvertently have made it difficult for these resources to be deployed. Understanding the existing regulatory barriers may lead to their removal. States such as Texas, New York, California, and others have already undertaken new regulatory approaches that simplify the technical integration of distributed resources into their local distribution networks. We encourage regulators and interested parties to become familiar with the work now under way in these states and to take steps to ease the integration of small-scale resources into local distribution systems.

The papers in the State Regulatory Policy and Distributed Resources series may be found at www.nrel.gov/publications under the following titles:

- $\quad$ Accommodating Distributed Resources in Wholesale Markets, NREL/SR-560-32497

- $\quad$ Distributed Resource Distribution Credit Pilot Programs - Revealing the Value to Consumers and Vendors, NREL/SR-560-32499

- $\quad$ Distributed Resources and Electric System Reliability, NREL/SR-560-32498

- Distribution System Cost Methodologies for Distributed Generation, NREL/SR-56032500

- Distribution System Cost Methodologies for Distributed Generation Appendices, NREL/SR-560-32501.

These reports, along with previous reports that address related distributed resource issues, can also be accessed on line at www.raponline.org. 


\section{Table of Contents}

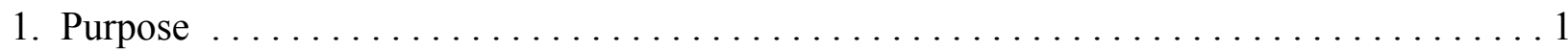

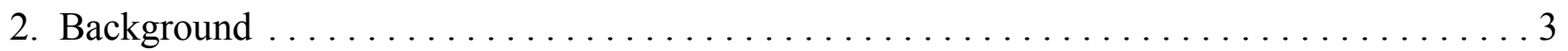

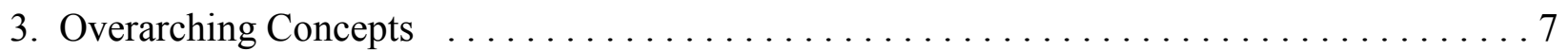

3.1. Regulators and Distribution Utilities Need to Know More About Underlying

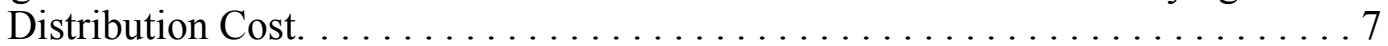

3.2. Distributed Resources Need to Be Considered in the Aggregate, not Individually. . 8

3.3. Now Is the Time to Begin Learning from Pilot Programs. . . . . . . . . . . . 10

4. Three Steps to a Distributed Resource Credit Pilot $\ldots \ldots \ldots \ldots \ldots \ldots \ldots \ldots \ldots \ldots \ldots$

4.1. Step One: Identify High-Cost Areas. . . . . . . . . . . . . . . . . . . . 11

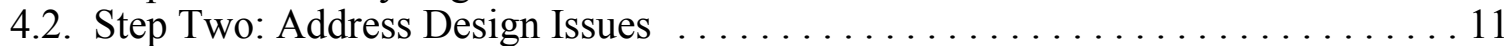

4.2.1. Types of Distributed Resources that Can Qualify. .............. 12

4.2.2. Operating and Performance Standards.................. 12

4.2.3. Installation Time, Milestones, and Minimum/Maximum Amount of

Response. .................................. 13

4.2.4. Duration of Distributed Resource Performance. . . . . . . . . . . . 13

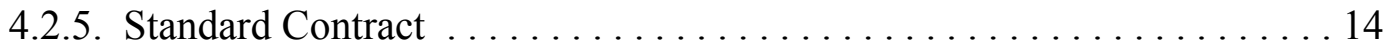

4.2.6. Bidding or Standard Payments. ..................... 14

4.3. Step Three: Develop a Monitoring and Evaluation Plan. . . . . . . . . . . 14

4.3.1. Distribution Plant Performance. ...................... 15

4.3.2. Distributed Resource Performance. . . . . . . . . . . . . . . . . . . 15

4.3.3. Distributed Resource Supply Curve. ................... 15

4.3.4. Distributed Resource Response Time. .................. 15

4.3.5. Service Quality and Outage Performance. ................ 15

4.3.6. Environmental Performance ....................... 15

4.3.7. Distributed Resource Vendor and User Feedback $\ldots \ldots \ldots \ldots \ldots 15$

4.3.8. Customer Profiles. . . . . . . . . . . . . . . . . . . . . . . 16

4.3.9. Tracking Cost Savings and Credit Payments. ................ 16

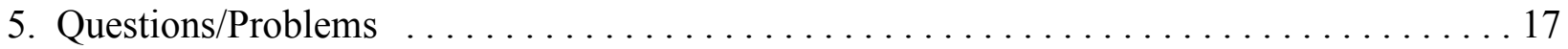

5.1. Do Deaveraged Credits Get Around the Problems of Deaveraged Prices? . . . . . 17

5.2. Do Deaveraged Credit Approaches Work in Areas of Greenfield Construction, or Are They Limited to Areas in Need of Upgrades? . . . . . . . . . . . . . 17

5.3. What if, After a Certain Number of Years, the Conventional Upgrade Is Done and the Distributed Resources Are no Longer Needed? ................ 18

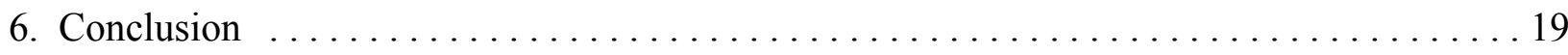




\section{Purpose}

The purpose of this report is to describe implementation options for two concepts: deaveraged distribution credits and distributed resource development zones. The concepts are closely related, and both were first described in Profits and Progress Through Distributed Resources, which was published by the National Association of Regulatory Utility Commissioners in February 2000. We believe that developing workable programs implementing these policies can dramatically increase the deployment of distributed resources in ways that benefit distributed resource vendors, users, and distribution utilities.

Distributed resources, which are small-scale generation and efficiency resources, have value in terms of energy, capacity, transmission, and distribution. If all these values could be tapped by distributed resource vendors or users, the lights would not have dimmed in California and consumer costs would be lower. The overarching problem is that vendors and users determine the "value" of distributed resources by comparing their costs to retail electricity prices, and those prices rarely bear a resemblance to actual marginal costs.

Although competition was supposed to open markets and opportunities for distributed resources, from the perspective of these resources, power sector restructuring has been more like power sector destructuring. Breaking the industry into separate entities subject to different jurisdictions has made it harder for distributed resource vendors and users to the see the full value of distributed resources. Capacity and energy issues are worked out in wholesale markets, power exchanges (PXs), independent system operators (ISOs), and the Federal Energy Regulatory Commission (FERC). These markets do not want to be bothered with the needs of tiny generators. Transmission issues are further complicated with ISOs, regional transmission organizations (RTOs), transmission owners, and uncertain FERC policy and jurisdiction. Amid the confusion, attention tends to be focused on large power and transmission projects rather than on the value offered by thousands, or perhaps millions, of distributed resources.

There is, however, some good news for distributed resources. First, distribution issues rest with the distribution utility and state regulators, and state utility regulators have been much more willing to remove barriers to the use of distributed resources. Second, in many locations the distribution value is so high that implementing the policies described in this paper may be enough to allow distributed resources to gain widespread use. 


\section{Background}

Regulators care about distributed resources for many reasons. High on the list are saving money, improving reliability, meeting customer needs, and improving the environment. And there are many more cost-effective opportunities for distributed resource deployment than are revealed by current pricing and cost recovery policies. Two important impediments are now well known: widespread deployment of distributed resources cuts distribution utility sales and puts profits at risk, and the high cost of strained distribution systems is not seen by consumers or vendors of distributed resources.

Average distribution rates are about $2.5 \notin$ per kilowatt-hour $(\mathrm{kWh})$, but marginal distribution costs vary substantially from one place to another and from one time to another. Marginal distribution system costs range from zero to substantially more than $20 \notin$ per $\mathrm{kWh}$.

Figures 1 and 2 are taken from Distribution System Cost Methodologies for Distributed Generation, which was published by the Regulatory Assistance Project (RAP) in 2001 and is a companion to this report in the RAP Distributed Resources Series. These figures show the average marginal cost of transformers and substations and lines and feeders, respectively, for 124 utilities. On a company-wide basis, the marginal costs are high and variable. For the entire group of 124 utilities, the average marginal costs for transformers, substations, lines, and feeders exceeds $\$ 700$ per $\mathrm{kW}$.

Figures 1 and 2

\section{Dis tribution of Growth in Transformers \& Substation Plant Investment Per MW Growth in System Peak (1995-1999)}

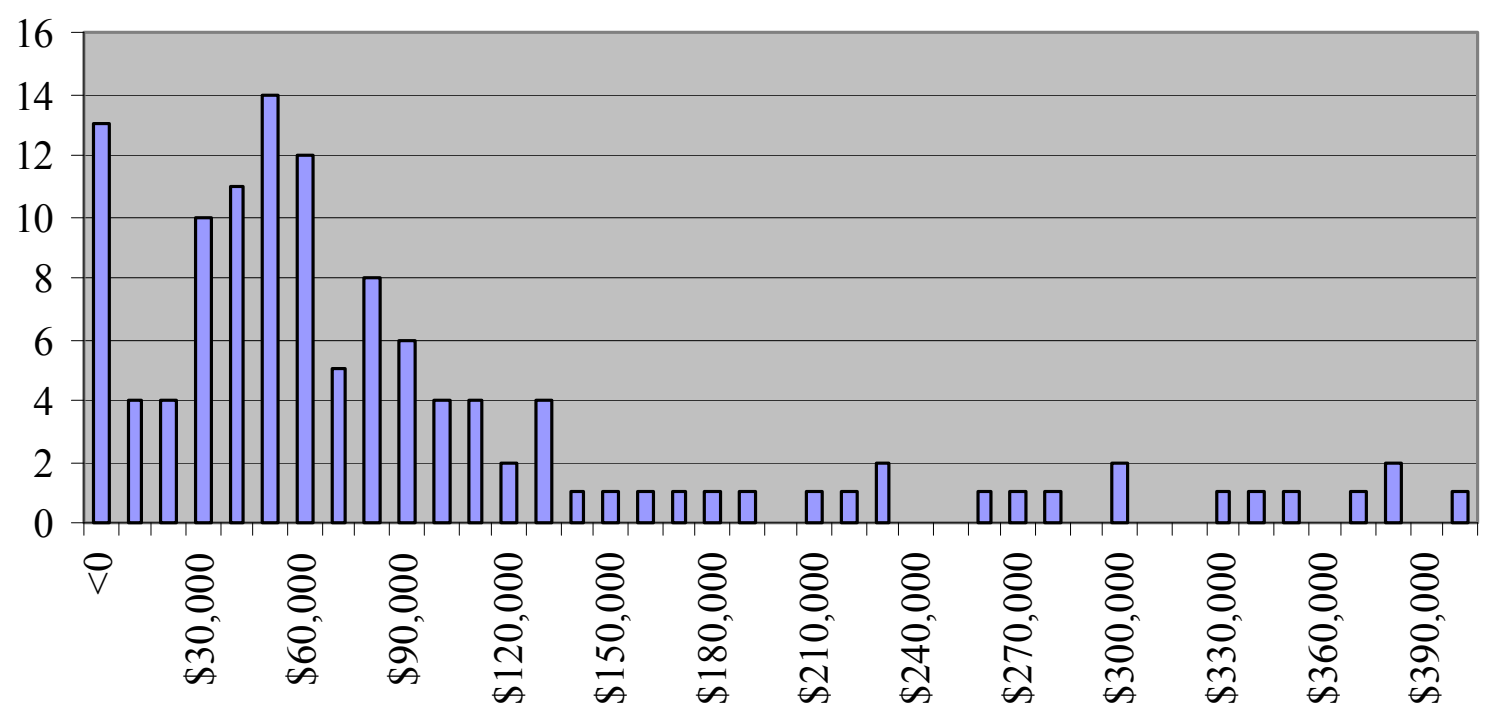




\section{Distribution of Growth in Lines \& Feeders Investment \\ Per Growth in System Peak \\ (1995-1999)}

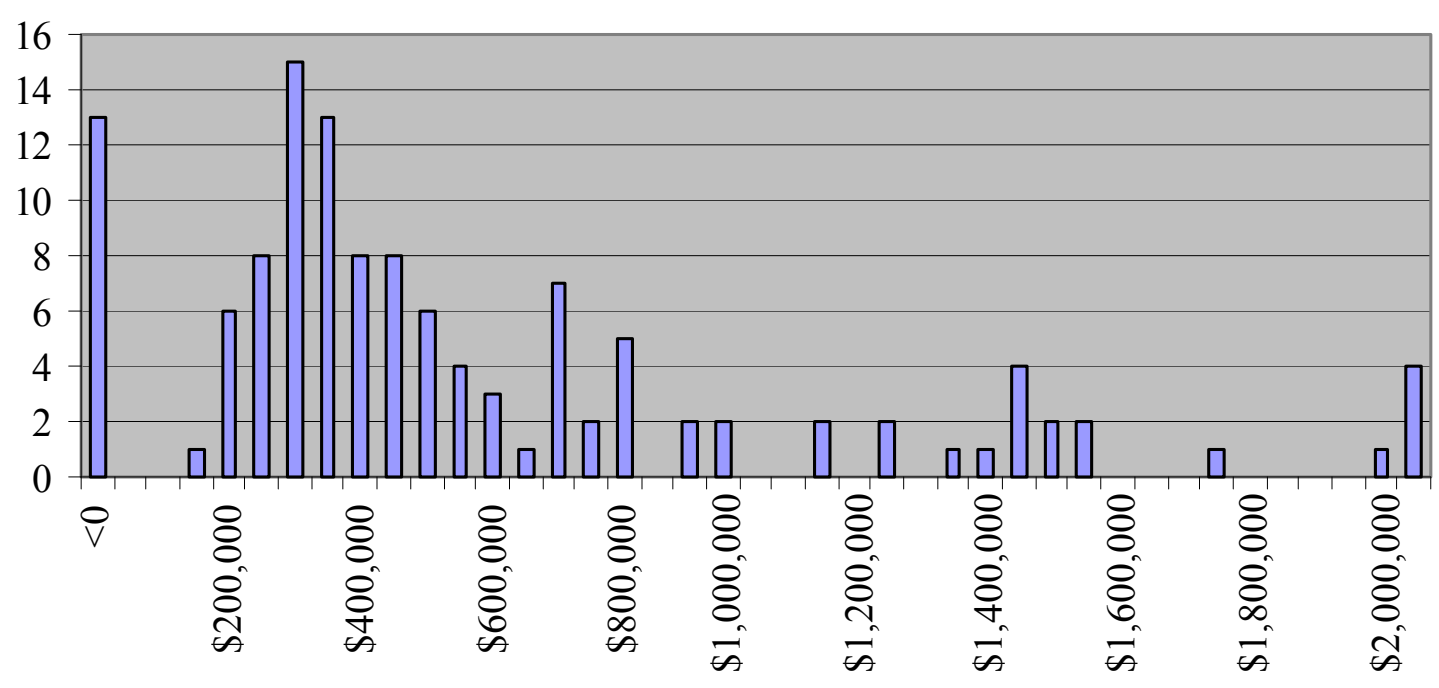

One of the main conclusions of Profits and Progress Through Distributed Resources is that deploying distributed resources only, or primarily, in high-cost areas would be a win-win situation for consumers and distribution utilities. The challenge is to develop policies to concentrate the use of distributed resources in high-cost areas. Deaveraged distribution credits and distributed resource development zones meet this challenge.

In theory, regulators could simply deaverage distribution prices, requiring the utility to charge something approaching zero in areas that have excess distribution capacity, and $20 \notin$ or more in areas with constrained distribution facilities. Deaveraged marginal cost prices would send the "right" price signals to consumers and ensure that distributed resources would be installed precisely when and where they make the most sense. Deaveraging prices along these lines, however, is unlikely and undesirable for compelling practical and political reasons.

Assuming that regulators do not deaverage distribution prices, state regulators-especially regulators trying to create competitive markets wherever possible-will confront a regulatory dilemma that a deaveraged credit scheme could solve.

On the one hand, distributed resources seem ideally suited to be delivered in a competitive fashion. They represent the antithesis of economies of scale. Distributed resources may be the ultimate form of retail competition because they can be used by consumers with or without industry restructuring. 
On the other hand, if distribution prices are not deaveraged, monopoly distribution utilities will have an unbeatable competitive advantage. Distribution system savings are key drivers of distributed resource economics, and distribution utilities are the only entities that know where the high-cost distribution areas are. With deaveraged distribution prices, all distributed resource vendors and users would see the value of distributed resources, and a vibrant competitive distributed resource market would develop. Without deaveraged distribution prices, distribution utilities are the only entities positioned to "see" the distribution value of distributed resource deployment. (They "see" the value in the form of distribution cost savings.) Thus, states that wish to encourage competitive delivery of distributed resources are compelled to either (1) deaverage distribution prices, which is unlikely for a long list of reasons; (2) prohibit distribution utilities from owning distributed resources, also unlikely, and it levels the field at the cost of eliminating all suppliers; or (3) adopt deaveraged distribution credits, a low-cost, low-risk strategy that might yield big benefits!

Deaveraged distribution credits and distributed resource development zones are practical alternatives to deaveraging all distribution prices. Under a program of geographically deaveraged distribution credits, the utility would establish financial credits for distributed resources installed in a given area.

The amount of the credit would be a function of the distribution cost savings generated by the distributed resources. Credits would be limited in duration and magnitude, in order to match the timing and need for distribution system reinforcements. For example, credits might be available to the first $20 \mathrm{MW}$ of distributed resources installed in the next year, because, after that period, loads are expected to grow to make the construction of new distribution lines unavoidable.

The amount of the credits should, at most, equal the value (savings) derived from deferring or avoiding the distribution upgrade. Credits would also vary according to the location of the distributed resource. Credits would be highest in the areas of greatest need and would be zero in low-cost areas. For example, customers in an area with $20 \notin$ distribution costs might be offered a $15 \notin$ credit. This would certainly be a strong economic incentive for customers and others to invest in distributed resources. Because the credit is $15 \phi$ instead of the $20 \phi$ the utility would incur to upgrade facilities, there is an opportunity for savings to be shared.

The term "deaveraged credits" is shorthand for a family of related policy options that provide cost-effective economic incentives to concentrate distributed resources in high-cost areas. Distributed resource development zones, for example, would designate geographic areas and set a standard credit for all qualifying distributed resources located in an area. A distribution value bidding scheme could be used to invite competitive proposals from distributed resource vendors. The amount of the credit requested in the bids would be one of the criteria used to select the winning distributed resources. 


\section{Overarching Concepts}

Regardless of the specific credit approach taken, regulators and distribution utilities need to know more about the underlying distribution costs, and distributed resources need to be considered in the aggregate, not individually. Now is the time to begin learning from pilot programs.

\subsection{Regulators and Distribution Utilities Need to Know More About Underlying Distribution Costs}

Every regulator has a good working knowledge of the cost of power from existing and new power plants. Increased attention to distributed resources in recent years means that regulators also probably have a reasonable sense of the cost of these resources. But the cost of upgrading and expanding distribution plants is not well known. However, if distributed resources can serve as a substitute for distribution investment, it is important to have some simple way to compare costs.

Figure 3

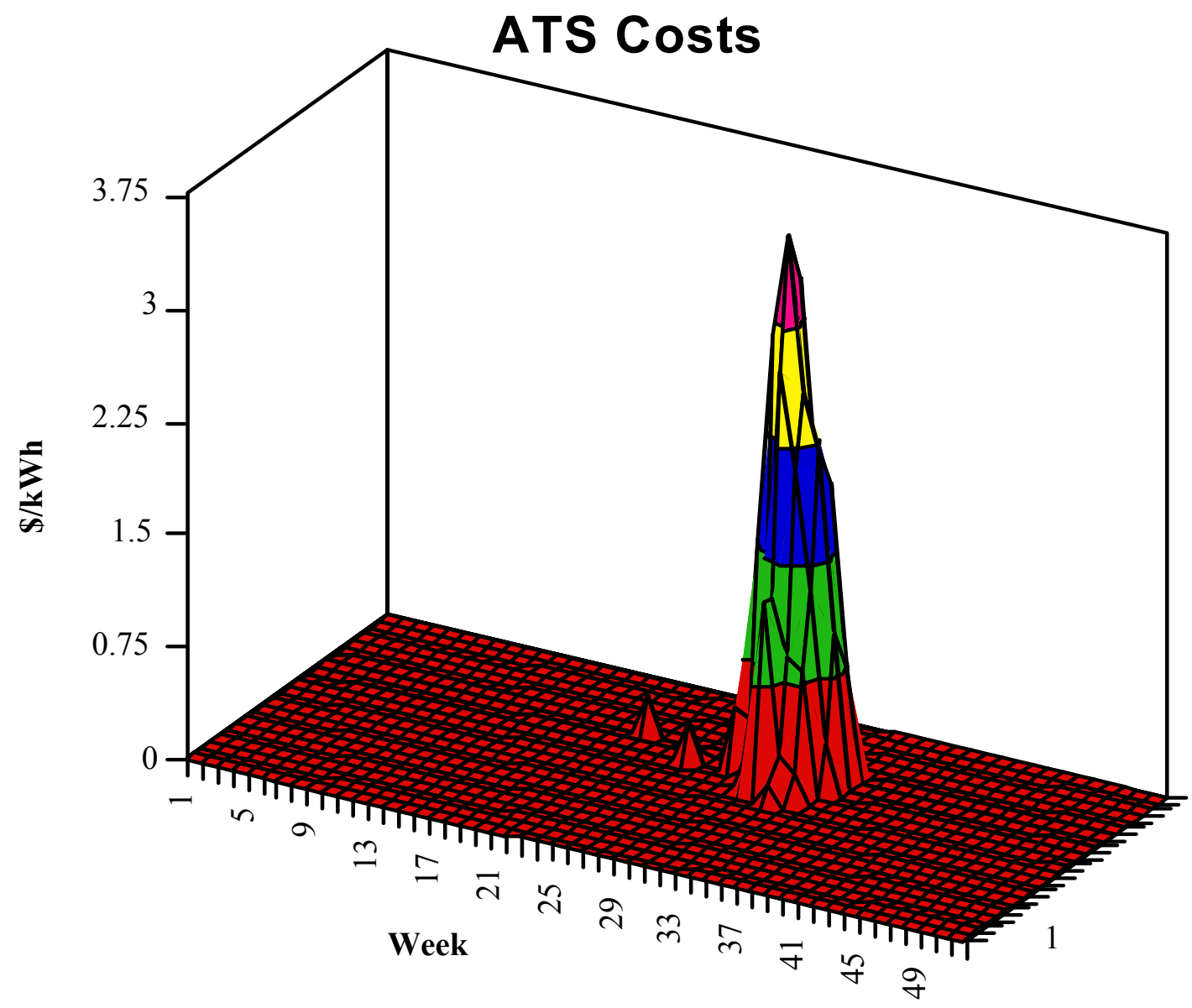


As shown in Figure 3, distribution costs can be thought of as a mountain of cash waiting to be mined by distributed resources. Concentrating distributed resources in these mountainous areas means that large savings can be realized. These savings can essentially be shared by the distribution utility, the consumer, and the distributed resource vendor.

The first task is to determine where and when the distribution system experiences high costs in order to focus the distributed resource program on the right geographic areas at the right time.

The value of distributed resources is determined by the answers to two questions: (1) What are the distribution marginal costs? (2) How will the aggregate performance of distributed resources lower or defer these costs? Two reports focus on these questions. The first is Costing Methodology for Electric Distribution System Planning, November 9, 2000, and the second is Distribution System Cost Methodologies For Distributed Generation, cited earlier.

\subsection{Distributed Resources Need To Be Considered in the Aggregate, Not Individually}

Although distributed resources can be relatively large-as much as $30 \mathrm{MW}$ or more-the difficult task, and hence the focus of this report, is to develop policies that work for the smallest units-those less than $100 \mathrm{~kW}$. At that size, the transaction cost of site-bysite, unit-by-unit consideration is high enough to kill even the most cost-effective installation. Unless we begin to approach these units in the way that we have historically approached similarly sized customer loads, the potential of a distributed resource industry will never be realized.

Distributed resources need to be treated the same way that we treat customer loads, in which broad aggregate customer uses are treated the same. Rate design, rate levels, and other tariff provisions are not considered on a customer-by-customer basis.

Thus, when we determine that a particular substation is or will soon be overloaded, it is not due to the load of any one customer; it is due to the aggregate load characteristics of a large group of customers.

\section{Some Simple and Immediate Steps}

Digging deep into distribution system costs can seem like a daunting and time-consuming task. Fortunately, there are several simple first steps that regulators can take immediately. First, require the distribution utility to file and periodically update a list of all major (more than $\$ 1$ million) distribution upgrades. These are the areas that are most likely to have the highest cost areas. For each area, the distribution utility should state what load reduction would allow the planned upgrades to be avoided or delayed. These are the load reductions that distributed resource vendors and users should be given an opportunity to serve.

Second, require the distribution utility to file and periodically update a list of the areas (by substation and feeder) that have the worst reliability record (in terms of outages). These may or may not be the same areas scheduled for distribution upgrades. If they are not areas scheduled to be upgraded, they may be candidates for distributed resources that can improve reliability.

Regulators in New South Wales, Australia, have recently adopted rules along these lines. See http://www.energy.nsw.gov.au /industry_performance/networks/ Recognised\%20DM\%20Code\%20May\%2001.pdf

Our ability and willingness to treat different customers differently is limited to the use of sophisticated time-of-use prices. With flat kWh 
prices, two customers that consume $1000 \mathrm{kWh}$ per month pay the same bill even if one uses power on peak and the other uses power off peak. With more sophisticated time-of-use prices, customers that use more power during peak periods pay more than customers that use less power on peak, even though the same prices apply to both. The decision to use flat or time-of-use prices is based on the size of the customers, the cost-effectiveness of the added investment in meters, customer acceptance, and fairness.

This is the same way we need to treat distributed resources. Small distributed resource prices or credits need to be considered on the basis of their aggregate performance or value.

\section{It Helps To Consider How We Treat Loads}

A typical electric water heater has a peak load of $4 \mathrm{~kW}$. It is either on or off. It is not under the direct control of the utility or the customer. It turns on and off when it wants to.

From the perspective of the distribution utility, the water heater turning on looks like a $4 \mathrm{~kW}$ generator turning off and vice versa. One could say that an electric water heater has almost all of the electrical characteristics of a very bad $4 \mathrm{~kW}$ distributed generator that runs only at full load or zero and turns on and off intermittently.

Although the operating characteristics of any one water heater are difficult to predict, the operation of all water heaters as a group is very easy to predict reliably. As a result, regulators have become very experienced at determining the cost the water heater imposes on the distribution system.

Imagine how many water heaters would be sold if each water heater had to be studied, separately metered, and had an individual rate determined for it before it was connected. No doubt the studies would show that houses with teenage children use more hot water than houses with no children. Perhaps there would be calls for child meters. Fortunately, the issue is handled in a much more practical way.

Regulators need to consider distributed resources using the very same approaches and techniques we use for water heaters.

The smallest residential-scale distributed resources would not be separately metered, and their value would be determined using the same kind of aggregate load research data used to set prices now for this customer class. An average residential customer may have a peak load of $10 \mathrm{~kW}$ and a diversified load of 3 or $4 \mathrm{~kW}$. Adding a small fuel cell, PV unit, or controlled water heater may lower the average peak load to $8 \mathrm{~kW}$ and the average diversified load to 2 or $3 \mathrm{~kW}$. The value of these very small units should be determined in this broad aggregate manner.

The same principles apply for larger distributed resources of 10 to $100 \mathrm{~kW}$ that may be in commercial settings. The primary difference is that these customers are more likely to be metered on a time-of-use basis, which means the value of their distributed resources will differ, depending on when their units operate. ${ }^{1}$

${ }^{1}$ The timing of the distribution peak may differ from the timing of the system peak. These timing differences need to be taken into account and perhaps reflected in time-of-use prices. 


\subsection{Now Is the Time to Begin Learning from Pilot Programs}

Using distributed resources to avoid or defer distribution investment is based on a solid theoretical and intellectual foundation but very little practical experience. What we need now are a variety of pilot programs aimed at documenting the extent to which distributed resources can defer or avoid investment while meeting customer needs in a safe and environmentally acceptable manner. Pilot programs by their very nature are experiments and need to be carefully designed to provide valuable information. 


\section{Three Steps to a Distributed Resource Credit Pilot}

\subsection{Step One: Identify High-Cost Areas}

Clearly, the first step is to examine capital investment plans and identify the parts of the distribution system that are most likely to benefit from the deployment of distributed resources. The earlier the areas can be identified, the better. Creating and implementing a pilot program will take some time, so at first it is better to look for areas that will require investment in the next 24 to 36 months, rather than areas that require investment in the next 30 to 90 days.

It makes sense to select pilot areas that are typical rather than those that have some unique characteristic. The purpose of the pilots should be to gain experience before expanding the program to full-scale use. This is best achieved by conducting the pilot in areas that have conditions similar to those that generally prevail.

As a general matter, the credits that could be made available should be capped at the cost savings that the distributed resource can produce. Three considerations, however, argue against delaying pilot programs while the distribution cost savings estimations are refined and improved.

First, estimating distribution cost savings is an evolving science. It may be years before a consensus is reached on the precise level of savings. In the meantime, a significant distribution investment is being made, and much of this investment could be wasted because cost-effective distributed resource alternatives are not being actively pursued.

Second, pilot programs by definition are learning experiences. It is more important for a pilot program to lead to cost-effective, full-scale programs than for it to be cost-effective. Any losses resulting from using too high a distributed resource credit would be limited by the very nature of a pilot. Any losses would also be offset by the educational value of such a program.

Third, the credit pilots we suggest initiating use standard offer credits or competitive bidding. In either case, the level of the credit is likely to be less than the maximum credit possible. If standard offers are made, the credits could be lower for some distributed resource technologies than for others. Similarly, if competitive bidding is used, the credit needed for some technologies will be less than the credit needed for other technologies. With either approach, the average credit is likely to be substantially less than the highest credit that could be justified.

\subsection{Step Two: Address Design Issues}

A number of important practical questions must be considered in designing a deaveraged-credit, market-based pilot program. For most issues, there is no single right or wrong answer. The best way to proceed is to ask the distribution utility and the interested distributed resource vendors and users to collaborate on pilot program design. The top six issue areas that need to be considered are described below. 


\subsubsection{Types of Distributed Resources that Can Qualify}

Not all distributed resources are created equal. The utility and the regulators need to decide which distributed resources can participate in a credit program. For example, the most common distributed resource today is an internal combustion (gasoline or diesel) engine connected to a generator. Environmentally, many of these types of units are very bad, yet because of their small size and historically very limited hours of operation, at present they do not require environmental permits.

It would be short-sighted to design and implement a distributed resource credit program if the result was to substantially increase the use of these types of distributed resources. It would not only be bad for the environment, but it would also probably hasten new environmental regulations that could undermine the value of the units to the utility and to the customer. A more prudent course would be to designate a class of qualifying distributed resources that would be eligible for the program and exclude distributed resources that may cause environmental or other problems. Another option is to establish a system of graduated payments, with higher payments to clean resources because they are more likely to result in the desired cost savings.

Qualifying resources should also include demand- and supply-side options. Some demand-side options, primarily involving load management, will be easy to incorporate. Indeed, many utilities already have credit approaches that offer customers a payment or reduced electricity price if they agree to have part of their load under direct control. Detroit Edison's controlled water heater program is a good example. These programs, however, have generally been designed with an eye toward reducing system peak energy and capacity costs rather than avoiding or deferring upgrades to the distribution plant. Changing the focus to distribution cost savings means that the loads may have to be curtailed during the distribution peak instead of the system peak.

\subsubsection{Operating and Performance Standards}

Referring again to the "mountain" of potential cost-of-service savings shown in Figure 3, it is clear that distributed resources can save money if they either generate power or reduce demand during high-cost periods. Thus, the terms of a deaveraged credit program should specify that the credit is tied to the distributed resource's ability to deliver its value during the hours that the substation or feeder is at or near peak load.

Several approaches can be taken, depending on the size and nature of the distributed resource. For the smallest units that are not directly under the user's control, such as PV, wind, CHP units, or units that are designed to run whenever available, this requirement should be determined in an aggregate, probabilistic manner. Some combination of load studies, manufacturer's availability data, and warranty information can be used to estimate the likely contribution during peak periods. If, for example, only $60 \%$ of the installed generation is likely to be on line during the peak periods, the credits paid to this class of facilities would be discounted. Special metering and individually determined credits could be options, but they should not be required.

For small units that are directly under the user's control, such as backup generators, it may be necessary to require some type of metering to verify the operation of the unit. For larger units installed on the premises of customers who are likely to have more sophisticated metering, credits could be paid on a metered time-of-use basis. This would result in higher credits paid to distributed resources that are operating more when needed. 
Also, many distributed resources are capable of being in direct two-way communication with the utility. Microturbines, fuel cells, and radio-controlled loads can all either be placed under direct utility control or they can at least be monitored by the utility in real time. This provides the best opportunity to manage the distributed resources to reduce distribution costs, and distributed resources with this type of capability should receive the highest possible credit.

\subsubsection{Installation Time, Milestones, and Minimum/Maximum Amount of Response}

Distributed resources can save money by avoiding or deferring distribution upgrades if enough of them are in place in time to avoid conventional upgrades. Conventional distribution system upgrades are planned and installed in a fairly short time period; one to three years is common.

This has several implications for a deaveraged credit program. First, it means the utility should have a well-developed distributed resource credit program prepared, approved by regulators, and ready to deploy in a given area as soon as an upgrade appears to be needed.

Second, deploying distributed resources will take time. How the market reacts to a credit program will be known with certainty only after the programs have been in use for some time. We believe, however, that the most likely scenario is that distributed resource vendors, rather than retail customers, will be the main users of the credit program. Once the availability and size of credits are known, vendors will begin the job of marketing their goods and services to end users. The credit will allow a distributed resource vendor to discount equipment and reach agreements quickly with end-use consumers.

Third, there may be some minimum amount of a distributed resource that must be made available before distribution savings can be realized. It seems reasonable that a deaveraged credit program would state the minimum amount of a distributed resource that must apply and qualify for the credits before any credits are paid. A reasonable set of milestones could be established to protect against a situation in which a certain minimum amount of a distributed resource is signed up for credits and then does not materialize. For example, if a project fails, another should be allowed to take its place.

To avoid paying for more distributed resources than are needed, the program could also state the maximum amount that will receive credits.

\subsubsection{Duration of Distributed Resource Performance}

In some cases, distributed resources will provide value because of their ability to allow utilities to postpone distribution upgrades for a few years. In this situation, the persistence of the distributed resource should not be much of an issue. In other cases, their value may be in providing a more permanent substitution for distribution investment. This would make the long-term reliability of the distributed resource more important.

There are at least two approaches to matching the performance of the distributed resource to the needs of the distribution system: contractual requirements and payment terms. A contract, including standard contracts for small units, could specify performance requirements, including long-term availability. Failure to meet the requirements could result in reduced or lowered payments or, if needed, fines and penalties. 
For larger units with time-of-use metering, long-term availability can probably best be addressed through credit payments. Credits are paid on the basis of measured performance relative to the needs of the distribution system. For example, if the distribution system experiences its peak loads on weekday afternoons during the summer, payments could be made based on the measured performance of individual distributed resources during these designated periods. If the credits were based on three years' worth of deferrals, the performance-based payments should be spread out over the entire three-year period. If the credit payments have been in the form of large up-front payments, the contract may provide for repayment of excess payments if the distributed resource ceases operation.

\subsubsection{Standard Contract}

To reduce transaction costs, it makes sense to have a simple, standard contract setting forth the duties and responsibilities of all parties. Having a standard contract also provides an opportunity for regulatory oversight and input from vendors and users into important contract terms.

Past experiences with small-scale wind and interconnected PV facilities and net metered facilities can provide substantial information about reasonable and unreasonable contracts. Contract terms covering metering and insurance can be made too onerous to be successful.

\subsubsection{Bidding or Standard Payments}

Credits could be paid on the basis of fixed preset credits, such as $\$ / \mathrm{kW} /$ year, for qualifying distributed resources. The fixed credits could be the same for all types of distributed resources, or they could differ for different classes of them. Higher credits for cleaner distributed resources or those using combined heat and power (CHP) might be a way to encourage these types of facilities.

The level of the payments could range from very low up to the estimated value of the distributed resource. The credits could also be the same in all designated areas, or they could differ on the basis of the relative need for distributed resources and the potential distributed resource cost savings. Offering different levels of credits in different locations would help create a supply curve for distributed resources, and it is probably justified by the differences among distribution cost savings.

Alternatively, payments could be made on the basis of competitive bids; the winning bids would be the distributed resources requesting the lowest credits. This approach has the appeal of offering the most value to consumers, but it also may have the highest transaction and administrative costs.

\subsection{Step Three: Develop a Monitoring and Evaluation Plan}

The purpose of pilot programs is to gather experience and information needed before policies are implemented broadly. Pilot deaveraged credit programs are especially useful in answering questions in a number of areas. 


\subsubsection{Distribution Plant Performance}

How does the operation of the distributed resource affect substation and feeder loadings? How is distribution affected during high load periods? During low load periods? Are there any unanticipated effects on the distribution plant? Would direct control of the distributed resource by the utility add any value?

\subsubsection{Distributed Resource Performance}

How well do distributed resources perform individually and in the aggregate? How many distributed resources does it take before aggregate performance is reliably predictable? How do distributed resources perform over time? Does the method of payment affect performance? How do different technologies perform? How well has distributed resource operation matched the needs of the distribution equipment? What types of distributed resources are able to be dispatched by the utility?

\subsubsection{Distributed Resource Supply Curve}

What is the relationship between the quantity of distributed resources and the level of the credits? Can supply curves for distributed resources be constructed? Can they distinguish between distributed resource technologies?

\subsubsection{Distributed Resource Response Time}

How long does it take from the time the need for a distributed resource is determined to the time it can be installed? How does the response time vary with the credit approach taken (bidding versus standard offer)? How does the response time differ for different types of distributed resources? How does the response time differ for various levels of credit?

\subsubsection{Service Quality and Outage Performance}

Has the distributed resource had a discernible effect on outages, frequency, restoration times, or power quality?

\subsubsection{Environmental Performance}

What are the emission characteristics of the distributed resource? Did the operation of the distributed resource raise environmental concerns for local residents or local environmental agencies? Was there any relationship between the level of the credit and the type of distributed resource deployed?

\subsubsection{Distributed Resource Vendor and User Feedback}

What problems did the pilot pose to distributed resource vendors and users? What suggestions were received to improve the program? Did the siting and operation of the distributed resource cause local noise, pollution, or other complaints? Did the distributed resource provide any other benefit to the user, such as power quality, backup service, heating, cooling, or motor drive? 


\subsubsection{Customer Profiles}

What types of customers have installed distributed resources? What types were able to use CHP distributed resources? What type of customer allowed the utility to dispatch the distributed resource?

\subsubsection{Tracking Cost Savings and Credit Payments}

Have estimated savings been achieved? If so, at what cost to the utility? And if so, at what cost to the customer? 


\section{Questions/Problems}

The deaveraged credit approach offers a practical way to give reasonable price signals to vendors and users of distributed resources. Still, a number of potential issues might not be resolved until we have some practical experience. The questions include:

\subsection{Do Deaveraged Credits Get Around the Problems of Deaveraged Prices?}

We do not believe that deaveraging distribution prices and fully reflecting locational marginal costs in consumer prices is a practical option. Prices would increase radically for some customers and decrease to nearly zero for others. Prices would also be very different from one neighborhood to another. Given the public's appetite for stable prices, price deaveraging is not feasible.

We believe that deaveraged credits could give distributed resource vendors and users the same economic signal but without the wide-scale disruption and public reaction of changing prices. We believe that the credit scheme would be more acceptable to the public for several reasons. First, the credit scheme would be more visible to vendors than to consumers. Most consumers would not be aware of the program, and if they were aware of it, it would have no effect on their monthly bill. With deaveraged prices, customers in the area would be notified of the their status in the most direct way possible-a large rate increase. Second, a high credit in one area and no credit in another can be explained as a lower-cost alternative to adding new poles and wires. Consumers are probably already aware that some areas are receiving new distribution investment and others are not. All consumers benefit by using the credit approach rather than investing in more costly conventional construction.

Whether the deaveraged credit approach is accepted by the public will not be known with certainty until utilities begin to experiment with it.

\subsection{Do Deaveraged Credit Approaches Work in Areas of Greenfield Construction, or Are They Limited to Areas in Need of Upgrades?}

New distribution equipment is expensive, and the need for adding new equipment distinguishes the high-cost areas from low-cost areas. There are two general types of high-cost distribution areas: existing parts of the system that need upgrading, and new greenfield sites, subdivisions, and line extensions where new distribution equipment must be installed for the first time.

Most of the description of a credit program is in the context of existing distribution areas in need of upgrading. Nevertheless, a credit program may also be useful in greenfield situations. That distributed resources are cost-effective substitutes for long line extensions is well known. Studies have shown that PV and energy efficiency is cost-effective in comparison with residential line extensions as short as 1/4 mile. As regulators and distribution utilities have eliminated subsidies for line extensions, public utility commissions (PUCs) have adopted rules requiring that customers receive full information before committing to a line extension. Some utilities also offer remote consumers stand-alone electric service based on PV or other distributed resources. 
More recent and more surprising are the studies showing that it is already cost-effective to serve new subdivisions using a combination of distributed resources. ${ }^{2}$

\subsection{What if, After a Certain Number of Years, the Conventional Upgrade is Done and the Distributed Resources Are no Longer Needed?}

In some situations, distributed resources may defer rather than eliminate the need for distribution system upgrades. The "growth spurts" of distribution plants mean that, once completed, the marginal cost of distribution drops to zero. Assuming that the credit correctly reflected the value of the deferral, the payments would cease after the deferral period. The decision could be made to operate or not operate the installed distributed resource on the basis of the remaining (nondistribution-related) economics.

${ }^{2}$ See "Why are Central Station Generation and T \& D Power Systems being Challenged?" Murray Davis, DTE Energy Technologies, IEEE Power Engineering Society, 2000 Summer Meeting, July 16-20, 2000, Seattle, Washington. 


\section{Conclusion}

Designing and implementing credit-based pilot programs for distributed resources distribution is a low-cost, low-risk opportunity to find out how these resources can help defer or avoid costly distribution upgrades. Distribution utilities, distributed resource vendors and users, and other stakeholders should work together to design and run pilot programs to gain knowledge and experience in this area. 


\section{REPORT DOCUMENTATION PAGE}

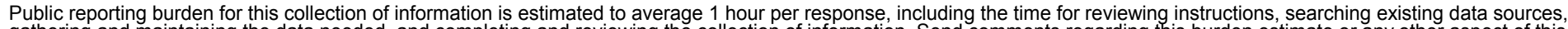

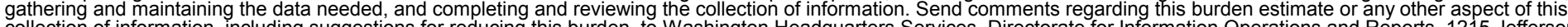
Davis Highway, Suite 1204, Arlington, VA 22202-4302, and to the Office of Management and Budget, Paperwork Reduction Project (0704-0188), Washington, DC 20503.
1. AGENCY USE ONLY (Leave blank)
2. REPORT DATE
October 2002
3. REPORT TYPE AND DATES COVERED Subcontract Report

4. TITLE AND SUBTITLE

State Electricity Regulatory Policy and Distributed Resources:

Distributed Resources Distribution Credit Pilot Programs — Revealing the Value to

Consumers and Vendors

6. $\operatorname{AUTHOR}(\mathrm{S})$

D. Moskovitz, C. Harrington, W. Shirley, R. Cowart, R. Sedano, and F. Weston

7. PERFORMING ORGANIZATION NAME(S) AND ADDRESS(ES)

The Regulatory Assistance Project

177 Water Street

Gardiner, Maine 04345

50 State Street

207-582-1135

Montpelier, Vermont 05602

802-223-8199

9. SPONSORING/MONITORING AGENCY NAME(S) AND ADDRESS(ES)

National Renewable Energy Laboratory

1617 Cole Blvd.

Golden, CO 80401-3393

5. FUNDING NUMBERS

CF: NAD-1-30605-03

TA: DP02.1001

8. PERFORMING ORGANIZATION REPORT NUMBER

\section{SUPPLEMENTARY NOTES}

NREL Technical Monitor: Thomas Basso

12a. DISTRIBUTION/AVAILABILITY STATEMENT

National Technical Information Service

U.S. Department of Commerce

5285 Port Royal Road

Springfield, VA 22161

13. ABSTRACT (Maximum 200 words)

Designing and implementing credit-based pilot programs for distributed resources distribution is a low-cost, low-risk opportunity to find out how these resources can help defer or avoid costly electric power system (utility grid) distribution upgrades. This report describes implementation options for deaveraged distribution credits and distributed resource development zones. Developing workable programs implementing these policies can dramatically increase the deployment of distributed resources in ways that benefit distributed resource vendors, users, and distribution utilities.

This report is one in the State Electricity Regulatory Policy and Distributed Resources series developed under contract to NREL (see Annual Technical Status Report of the Regulatory Assistance Project: September 2000-September 2001, NREL/SR-560-32733). Other titles in this series are:

- Accommodating Distributed Resources in Wholesale Markets, NREL/SR-560-32497

- Distributed Resources and Electric System Reliability, NREL/SR-560-32498

- Distribution System Cost Methodologies for Distributed Generation, NREL/SR-560-32500

- Distribution System Cost Methodologies for Distributed Generation Appendices, NREL/SR-560-32501.

14. SUBJECT TERMS

distributed energy resources; DER; distributed resources; distributed generation; distributed power, credit-based pilot programs; deaveraged distribution credits; interconnection; utility grids; regulatory policy; public utility commissions; electric industry restructuring; National Renewable Energy Laboratory; NREL

17. SECURITY CLASSIFICATION OF REPORT Unclassified
18. SECURITY CLASSIFICATION OF THIS PAGE Unclassified
19. SECURITY CLASSIFICATION OF ABSTRACT

Unclassified
15. NUMBER OF PAGES

16. PRICE CODE

UL

Standard Form 298 (Rev. 2-89) Prescribed by ANSI Std. Z39-18 